\title{
Grapevine Phenolic Compounds in Xylem Sap and Tissues Are Significantly Altered During Infection by Xylella fastidiosa
}

\author{
Christopher M. Wallis and Jianchi Chen
}

United States Department of Agriculture-Agricultural Research Service, San Joaquin Valley Agricultural Sciences Center, 9611 S. Riverbend Ave., Parlier, CA 93648.

Accepted for publication 25 May 2012.

\section{ABSTRACT}

Wallis, C. M., and Chen, J. 2012. Grapevine phenolic compounds in xylem sap and tissues are significantly altered during infection by Xylella fastidiosa. Phytopathology 102:816-826.

Pierce's disease of grapevine (PD), caused by the bacterial pathogen Xylella fastidiosa, remains a serious problem for grape production in California and elsewhere. This research examined induction of phenolic compounds in grapevines ('Thompson Seedless') infected with $X$. fastidiosa over a 6-month period. Two months postinoculation with $X$. fastidiosa, catechin, digalloylquinic acid, and astringin were found at greater levels in xylem sap; multiple catechins, procyanidins, and stilbenoids were found at greater levels in xylem tissues; and precursors to lignin and condensed tannins were found at greater levels in xylem cell walls. However, such large-scale inductions of phenolic compounds were not observed 4 months after inoculation. Six months after inoculation, infected plants had significantly reduced phenolic levels in xylem sap and tissues when compared with control plants, including lowered levels of lignin and condensed tannins. At 6 months, PD symptoms were severe in infected plants and most photosynthetic tissue was abscised. These results suggest that, even though grapevine hosts may initially respond to $X$. fastidiosa infections with increased production of phenolic compounds, ultimately, PD causes grapevines to enter a state of decline whereby diseased hosts no longer have the resources to support secondary metabolite production, including defense-associated phenolic compounds.
Pierce's disease (PD), caused by the xylem-limited bacterium Xylella fastidiosa Wells et al., remains a serious threat to the $\$ 3$ billion Californian grape (Vitis vinifera L.) industry (8). One recent epidemic caused a loss of $30 \%$ of vineyards in Temecula Valley, CA for an estimated cost of $\$ 46$ million $(8,40)$.

Despite recent research on PD in California, including efforts to breed resistance into commercial grapevines $(11,15,27,41)$, little is known about grapevine responses to $X$. fastidiosa infection. Furthermore, it is unclear what, if any, induced defense responses occur in the xylem of $X$. fastidiosa-infected grapevines and whether or not such defense responses can limit $X$. fastidiosa infections or the progression of PD.

Recent efforts have examined key components of grapevine resistance to $X$. fastidiosa infection; in particular, the upregulation of certain defense-associated proteins or RNAs following infection $(5,26,45)$. Furthermore, the role of grapevine xylem anatomy in effecting $X$. fastidiosa intra-plant movement also has been confirmed $(4,9,38)$.

This current study complements previous grapevine resistance research by exploring the role secondary metabolites could play in pathogen-induced host defense responses that could occur during $X$. fastidiosa infections. Phenolic compounds produced by grapevines range from cell-wall-thickening compounds such as lignin (and its coumaric acid derivative precursors) and tannins

Corresponding author: C. M. Wallis

E-mail address: christopher.wallis@ars.usda.gov

Mention of trade names or commercial products in this publication is solely for the purpose of providing specific information and does not imply recommendation or endorsement by the United States Department of Agriculture (USDA). USDA is an equal opportunity provider and employer.

http://dx.doi.org/10.1094/PHYTO-04-12-0074-R

This article is in the public domain and not copyrightable. It may be freely reprinted with customary crediting of the source. The American Phytopathological Society, 2012. (both condensed and hydrolysable) to compounds associated with antibiotic activity (e.g., stilbenoids and flavonoids) (2). Many of these phenolic compounds were shown to be induced when grapevines were infected by fungal pathogens such as Botrytis cinerea $(12,21,24,34,39)$, viruses (17), and phytoplasmas (33). Presumably, grapevines produce greater amounts of phenolic compounds following infections because these compounds act to inhibit, impair, or otherwise kill pathogens. Some grapevine phenolic compounds were positively associated with resistance to infection by pathogens such as $B$. cinerea, Plasmopara viticola, and Erysiphe spp. $(13,14,16,35,36)$. Furthermore, phenolic compounds were observed to limit the in vitro growth of certain pathogens $(1,30,31)$, including $X$. fastidiosa (28). One of the most important grape phenolics in host defense against pathogens is resveratrol, a phytoalexin stilbenoid called the "key to resistance in grape" (18).

Because of the well-documented roles that phenolics have in providing resistance to other pathogens (2), the objective of this study was to observe changes in concentrations of grapevine xylem phenolics that occur following inoculation with $X$. fastidiosa. Phenolics were monitored within xylem sap, tissue, and cell walls 2,4 , and 6 months after initial inoculation to observe any changes and determine whether they were consistent. We hypothesized that infected grapevines possess greater phenolic concentrations in xylem sap and tissues (both methanol-soluble and cell-wallembedded phenolics). Few studies have focused on woody plant biochemical responses to xylem-dwelling bacteria. Therefore, this study is important because it not only expands our understanding about the host-pathogen interactions that occur in grapevines infected with $X$. fastidiosa but also expands our knowledge about plant responses that occur to xylem-fastidious bacteria in general.

\section{MATERIALS AND METHODS}

Plant materials and experimental design. In total, $30 \mathrm{~V}$. vinifera 'Thompson Seedless' vines (on 'Freedom' rootstock) 
were arranged in two completely randomized blocks within a climate-controlled greenhouse running a 14-h day-length cycle. Thompson Seedless grapevines were chosen because this cultivar was previously observed to be moderately tolerant of $X$. fastidiosa infection $(3,23,32)$. In November 2010, half of the plants in each block were mechanically inoculated with the Stag's leap strain of $X$. fastidiosa by using a modification of the pin-prick method of Hopkins (20), using water to resuspend bacterial cultures prior to infection. Three inoculations were made of the scion just above the rootstock and, to increase success, grapevines were not watered $24 \mathrm{~h}$ prior to inoculation. The other half of the plants were mock inoculated similarly with water. Two weeks after the initial inoculations, the inoculation treatments were repeated to further increase inoculation efficiency. One month after the initial inoculation and 2 weeks after the second inoculation, $X$. fastidiosa infection success was determined using enzyme-linked immunosorbent assay (ELISA) and polymerase chain reaction (PCR) according to the methods described below.

At 2, 4, and 6 months after the initial inoculation, 10-cm-long shoot samples, weighing $\approx 10 \mathrm{~g}$ each, were collected from all plants $\approx 30 \mathrm{~cm}$ apically from the inoculation point. Different shoots were sampled at each time. Collected samples were placed into $15-\mathrm{ml}$ centrifuge tubes, immediately flash frozen in liquid nitrogen, and stored at $-20^{\circ} \mathrm{C}$ until chemical analyses.

At the same time, an additional $5 \mathrm{~g}$ of plant material was harvested directly underneath the chemistry samples and immediately processed for both ELISA and PCR in order to detect $X$. fastidiosa. ELISA detection was made following the manufacturer's instructions using ELISA kits from Promega Corp. (Fitchberg, WI). PCR was conducted using the methods and primers as described by Chen et al. (10). Plants inoculated with $X$. fastidiosa that failed to test positive for $X$. fastidiosa were excluded from chemical analyses.

At the completion of the experiment (6 months), plants were evaluated for PD symptoms by placing them into one of the following categories: 0 (no disease), 1 ( $<25 \%$ symptomatic leaf tissue), 2 (25 to $50 \%$ symptomatic leaf tissue), 3 (51 to $75 \%$ symptomatic leaf tissue and some stunting of new shoots), 4 (76 to $100 \%$ symptomatic leaf tissue and severe stunting of shoots), or 5 (dead). Dead plants were excluded from chemical analyses. Some noninfected controls received non-zero ratings because symptom ratings were independent of tests for $X$. fastidiosa.

Chemical analyses. The frozen shoots were debarked by peeling away the outermost (phloem and bark) layers with a straight razor, and the denuded wood segments were then divided into two equal portions. One wood segment was cut into portions to fit inside $1.5-\mathrm{ml}$ centrifuge tubes with 5 to 10 glass beads on the bottom. These tubes were centrifuged at $12,000 \times g$ for $5 \mathrm{~min}$ at $4^{\circ} \mathrm{C}$ to cause the xylem sap to leave the xylem tissue and collect in the bottom of the tubes. The xylem sap was moved to clean tubes and diluted 1:1 ( $\mathrm{vol} / \mathrm{vol})$ in water for high-performance liquid chromatography (HPLC) analyses as described below.

The remaining (uncentrifuged) tissue was ground to a powder in liquid nitrogen with a mortar and pestle grinder (Retsch, Newtown, PA). The ground tissue was weighed out into two $100-\mathrm{mg}$ aliquots in separate microcentrifuge tubes. One of these tubes received $500 \mu \mathrm{l}$ of methanol (Thermo-Fisher Inc., Pittsburgh, PA) and was stored overnight at $4^{\circ} \mathrm{C}$, had the methanol removed to a clean tube, and then was re-extracted with an additional $500 \mu \mathrm{l}$ of methanol overnight at $4^{\circ} \mathrm{C}$ (for a total of $1 \mathrm{ml}$ of methanol in a combined extract). The remaining pellet was extracted for cell-wall-bound phenolics (6) by washing once in $1 \mathrm{ml}$ of water, then in $1 \mathrm{ml}$ of methanol, and finally in $1 \mathrm{ml}$ of tert-butyl methyl ether (Sigma-Aldrich, St. Louis). After drying overnight in a chemical hood, the pellet was resuspended in $400 \mu \mathrm{l}$ of $1 \mathrm{~N} \mathrm{NaOH}$ (Sigma-Aldrich) with $100 \mathrm{mM}$ ascorbic acid (Sigma-Aldrich) and $0.2 \%$ (vol/vol) of $\mathrm{NaBH}_{4}$ (Sigma-Aldrich). This sample incubated for $24 \mathrm{~h}$ on a shaker at $40^{\circ} \mathrm{C}$, after which the solution was acidified with $400 \mu \mathrm{l}$ of $1.5 \mathrm{M}$ formic acid (Sigma-Aldrich) and then $200 \mu \mathrm{l}$ of methanol was added. After centrifugation, the cell-wall-bound phenolic solution was transferred to a clean tube before analysis by HPLC, as described below.

The remaining pellet from the previous extraction was washed twice in water, treated with $800 \mu \mathrm{l}$ of $2 \mathrm{~N} \mathrm{HCl}$ (Sigma-Aldrich) and $300 \mu \mathrm{l}$ of thioglycolic (mercaptoacetic) acid (Sigma-Aldrich), then heated at $86^{\circ} \mathrm{C}$ for $4 \mathrm{~h}$ to extract lignin $(6,42)$. The suspension was centrifuged and the supernatant removed. The pellet was washed twice in $1 \mathrm{ml}$ of water, resuspended in $1 \mathrm{ml}$ of $0.5 \mathrm{M}$ $\mathrm{NaOH}$, and shaken for $18 \mathrm{~h}$. The $\mathrm{NaOH}$ supernatant was then removed and transferred to clean 2-ml centrifuge tubes, and the pellet was again suspended in $0.5 \mathrm{ml}$ of $0.5 \mathrm{M} \mathrm{NaOH}$ and shaken for $18 \mathrm{~h}$. Both extracts were combined for a total of $1.5 \mathrm{ml}$ of supernatant. To this supernatant, $300 \mu \mathrm{l}$ of $12 \mathrm{~N} \mathrm{HCl}$ was added and the mixture was incubated at $25^{\circ} \mathrm{C}$ for $4 \mathrm{~h}$. The tubes were centrifuged $(12,000 \times g$ for $5 \mathrm{~min})$, the supernatant was removed, and the pellet was resuspended in $1 \mathrm{ml}$ of $0.5 \mathrm{M} \mathrm{NaOH}$. Then $100 \mu \mathrm{l}$ of this solution was pipetted into a 2-ml cuvette with $1.9 \mathrm{ml}$ of $0.5 \mathrm{M} \mathrm{NaOH}$ and absorbance was read at $280 \mathrm{~nm}$ using a Libra S22 spectrophotometer (Biochrom, Miramar, FL). Absorbance values were recorded and compared with a standard curve of lignin (Sigma-Aldrich) suspended in $0.5 \mathrm{M} \mathrm{NaOH}$ at concentrations of $20,40,80,160$, or $320 \mu \mathrm{g} / \mathrm{ml}$ in order to calculate the total weight of lignin in each sample.

The second aliquot of $100 \mathrm{mg}$ of finely ground xylem tissue was extracted for condensed tannins using the methods of Wallis et al. (44). In brief, the samples were twice extracted in $0.5 \mathrm{ml}$ of $70 \%$ acetone (Sigma-Aldrich) overnight at $4^{\circ} \mathrm{C}$. The combined 1 $\mathrm{ml}$ of $70 \%$ acetone extract was then washed once with $0.5 \mathrm{ml}$ of petroleum ether (Sigma-Aldrich), followed by a wash with $0.5 \mathrm{ml}$ of ethyl acetate (Sigma-Aldrich), centrifuging at 10,000 $\times g$ after each wash to cause phase separation. The top organic solvent phase was discarded each time. The remaining acetone solution was evaporated overnight in a fume hood. To the remaining solution, $0.5 \mathrm{ml}$ of water was added. Of this solution, $0.2 \mathrm{ml}$ was added to $1.2 \mathrm{ml}$ of acidified n-butanol (95:5 [vol/vol] n-butanol:12 $\mathrm{N} \mathrm{HCl}$ [Sigma-Aldrich]), and $20 \mu \mathrm{l}$ of iron reagent ( $2 \%$ [wt/vol] ferric ammonium sulfate dodecahydrate salt [Sigma-Aldrich] diluted in $2 \mathrm{M} \mathrm{HCl}$ ). This mixture was vortexed until the solution turned clear, and it was then heated at $95^{\circ} \mathrm{C}$ for $1 \mathrm{~h}$. Each sample solution then had $100 \mu \mathrm{l}$ pipetted into a microplate and absorbance was read at $550 \mathrm{~nm}$ using a Biotek Epoch reader (Winooski, VT). Condensed tannin standards were prepared using the ytterbium acetate-based gravimetric method (44), and used to establish condensed tannin standard curves (tannin amounts were adjusted 1:1 in order to account for the weight of bound ytterbium acetate).

The xylem sap, methanol extracts, and cell-wall-bound extracts were analyzed by HPLC as described by Wallis et al. (43), with a few modifications. In total, $50 \mu \mathrm{l}$ of each sample was injected into a Shimadzu (Columbia, MD) LC-20AD dual-pump system equipped with an SIL-20A HT auto-sampler cooled to $4^{\circ} \mathrm{C}$, a Shimadzu Shim-Pack XR-ODS 4.6-by-100-mm column in a CTO-20 column oven set at $50^{\circ} \mathrm{C}$, and an SPD-20A photodiode array detector. A binary gradient with a flow rate of $1.0 \mathrm{ml} / \mathrm{min}$ was used, with an initial hold for 2 min of $95 \%$ solvent A (water with $2 \%$ [vol/vol] acetic acid) (Sigma-Aldrich), changing to $52.5 \%$ solvent B (methanol with $2 \%$ [vol/vol] acetic acid) over the next $20 \mathrm{~min}$, then changing to $100 \%$ solvent B over the next $10 \mathrm{~min}$, holding at $100 \%$ solvent B for $3 \mathrm{~min}$, and finally changing back to $95 \%$ solvent A over 5 min to prepare for the next run (a total run time of $\approx 40 \mathrm{~min}$ ). Compounds were quantified with the SPD-20A scanning at 280 or $320 \mathrm{~nm}$ depending on the compound. Additional wavelengths such as 370 and $525 \mathrm{~nm}$ also were monitored but no peaks were consistently observed at highenough levels to be quantifiable at these wavelengths. The threshold for quantification by peak areas was $\approx 10,000 \mathrm{mAU} / \mathrm{min}$; 
therefore, compounds whose peak areas were below this value were not quantified.

Peaks were putatively identified to compounds by matching UV/Vis spectra, relative retention times, and masses as determined by running voucher xylem sap, tissue, and cell wall samples on a Shimadzu LCMS-2020 HPLC-mass spectrometer, running the same gradient program as that of the HPLC analyses. The liquid chromatography-mass spectrometry analysis used an ESI probe, and masses for each peak were matched to compounds previously identified as occurring in grapevine (e.g., those described by Ali et al. [2]). Unequivocal identifications of peaks to compounds was made by matching retention times, UV/Vis spectra, and masses with those of known standards for the following compounds: caffeic acid, catechin, caftaric acid (albeit not to enantiomers), chicoric acid, coumaric acid, epicatechin, epicatechin gallate, ferulic acid, gallic acid, isoquercetin, piceid, procyanidin $\mathrm{B} 1$, procyanidin $\mathrm{B} 2$, procyanidin $\mathrm{C} 1$, quercetin, quinic acid, and resveratrol (trans-resveratrol) (all from Sigma-Aldrich). All other identified compounds (e.g., astilbin, coutaric acid, fetaric acid, and other procyanidins) were unable to be obtained commercially and, therefore, remain putatively identified. Some peaks were unable to be matched to compounds that are known to occur in grapevines and, therefore, were labeled as unknowns.

Compounds were quantified using equations generated from analyses of standard curves at the appropriate wavelength (either 280 or $320 \mathrm{~nm}$ ). Catechin, epicatechin, and other flava-3-ols were converted to gram amounts by using a standard curve of catechin; procyanidins (both dimer and trimer forms) were converted based on a standard curve of procyanidin B2; other flavonoids were converted using standard curves from quercetin or quercetin-3- $\beta$ D-glucoside; caftaric, coutaric, and fetaric acids were converted to gram amounts using a standard curve of caftaric acid; other coumaric acid derivatives were converted to gram amounts using a standard curve of ferulic acid; hydrolysable tannins compounds were converted using a standard curve of ellagic acid; stilbenoids were converted using a standard curve of resveratrol; and chicoric acid was converted using a standard curve of itself. Unknown compounds were not converted to gram amounts, and were analyzed by raw peak areas (mAU/min) at 280 or $320 \mathrm{~nm}$.

Concentrations of compounds in the same phenolic class were summed together for statistical analyses, depending on the sample, as follows: procyanidins and catechins (flava-3-ols), other flavonoids, hydroxycinnamoyltartaric acids (e.g., caftaric, coutaric, or fetaric acids), coumaric acid derivatives, hydrolysable tannins or precursors (including ellagitannins), or stilbenoids. In cases where certain compounds were unable to be resolved from a particular plant, that plant was excluded from analyses of grouped compounds to avoid an inaccurate sum due to missing data.

Statistical analyses. For all statistical analyses, SPSS (ver. 19.0; IBM, Armonk, NY) was used with $\alpha=0.05$. All data were screened prior to analyses using the EXPLORE feature for normality confirmation and outlier removal, with outliers defined as data points occurring greater than two standard errors away from the mean. Because each plant was sampled multiple times, repeated-measures analyses of variance (ANOVAs) were performed to examine differences resulting from inoculation treatment and multiple sampling of the same plant. However, because the same shoots were not measured at each time, univariate ANOVAs (model: sampling time, inoculation treatment, spatial block, and all interactions) also were utilized to assess total effects of sampling time and infection status for each compound and compound grouping. When spatial block terms (both block effect and interactions) were not significant, they were excised from ANOVAs. Due to strong effects of time and time-treatment interactions, each sampling time had infection status assessed by $t$ tests to observe significant differences for a single sampling time $(2,4$, or 6 months). Final PD ratings were associated with phenolic levels at 6 months postinoculation using Spearman's rho correlations.

\section{RESULTS}

Inoculation success. Of the 15 grapevines inoculated, 12 were positive for $X$. fastidios $a$ infection at all the sampling times. Three plants were initially positive at the beginning of the study (1 month after the first inoculation) but ceased to be ELISA and PCR positive when samples were collected at 2 months and, therefore, were excluded from subsequent analyses. One infected plant was excluded at 6 months because it was dead but, because it was still alive at 2 and 4 months, its chemistry was assessed at those times. At 6 months, 3 of the 11 remaining infected grapevines received the disease severity rating of 1,4 received a rating of 2, 3 received a rating of 3, and 1 received a rating of 4 .

Xylem sap phenolics. In total, 25 phenolic compound peaks were quantified for the xylem sap samples (Table 1). Repeatedmeasures ANOVAs determined that there were no significant effects $(P<0.05)$ of $X$. fastidiosa inoculation on chemistry, with the exception of the compound catechin $(F=5.837, P=0.027$, $N=20$ ).

Nonrepeated-measures univariate ANOVAs determined that time was a major source of variation for sap concentrations of total phenolics $(F=4.477, P=0.016, N=63)$, catechins and procyanidins $(F=3.441, P=0.038, N=69)$, hydroxycinnamoyltartatic acids $(F=27.326, P<0.001, N=72)$, flavonoids $(F=$ 15.896, $P<0.001, N=69)$, and hydrolysable tannins $(F=9.702$, $P<0.001, N=73$ ) (Fig. 1). All individual compound concentrations also were significantly $(P<0.05)$ affected by time, with the exception of procyanidin $\mathrm{B} 1$, a procyanidin $\mathrm{C}$ isomer, epicatechin, caftaric isomer 1 , a coutaric acid dimer, engeletin, and unknown 2. $X$. fastidiosa infections significantly increased levels of procyanidin B1 $(F=4.097, P=0.047, N=70)$, procyanidin $\mathrm{C} 1$ $(F=5.950, P=0.017, N=72)$, and catechin $(F=4.720, P=$ $0.033, N=73)$. Analyses of catechin concentrations revealed a significant $(P<0.05)$ interaction between time and infection treatment, whereas analyses of procyanidin $\mathrm{B} 1$ and procyanidin $\mathrm{C}$ isomer did not reveal any significant interactions. Spatial block effects and block-treatment interactions were not significant $(P<$ 0.05 ) and, therefore, were removed from ANOVAs.

The $t$ tests of the separate sampling times revealed that concentrations of total phenolics, catechins and procyanidins, and hydroxycinnamoyltartaric acids were not affected by Xylella infection 2 or 4 months postinoculation; however, significantly fewer levels of these compound groups were observed in infected plants compared with noninfected controls 6 months after inoculation treatment (Fig. 1). Concentrations of catechin, digalloylquinic acid, and astringin were greater in sap from infected plants 2 months after inoculation treatments, and catechin concentrations were greater in infected plants 4 months after inoculation (Table 2). One unknown (unknown 1) had greater sap levels in infected plants than noninfected plants 2 months postinoculation treatment $(t=2.666, P=0.014, N=24)$. In contrast, sap concentrations of procyanidin $\mathrm{B} 1$, a procyanidin $\mathrm{C}$ isomer, procyanidin $\mathrm{C} 1$, two caftaric acid isomers, and digalloylquinic acid were significantly less in infected plants than noninfected plants 6 months postinoculation (Table 2).

Xylem tissue phenolics. In total, 22 phenolic compound peaks were quantified for finely ground xylem tissue samples (Table 1). Repeated-measures ANOVAs determined that $X$. fastidiosa infection significantly increased concentrations of total non-catechin flavonoids $(F=5.682, P=0.030, N=18)$, total stilbenoids $(F=$ 6.167, $P=0.024, N=18)$, gallic acid hexoside $(F=5.100, P=$ $0.045, N=13)$, taxifolin pentoside $(F=16.393, P=0.002, N=$ 14), resveratrol $(F=5.674, P=0.035, N=14)$, and an astringin dimer $(F=7.444, P=0.018, N=14)$ in xylem tissue.

Nonrepeated-measures univariate ANOVAs observed time to be a major source of variation for concentrations of total phenolics ( $F=20.890, P<0.001, N=58)$, total catechins and procyanidins $(F=17.243, P<0.001, N=64)$, coumaric acid derivatives $(F=$ 
7.163, $P=0.002, N=63)$, other flavonoids $(F=20.690, P<$ $0.001, N=67)$, and stilbenoids $(F=11.876, P<0.001, N=64)$ (Fig. 1). All individual compound concentrations also were significantly $(P<0.05)$ influenced by sampling time, with the exception of catechin and astringin. $X$. fastidiosa infection significantly increased levels of coumaric acid derivatives $(F=$ 4.765, $P=0.033, N=63)$, other (non-catechin) flavonoids $(F=$ 4.155, $P=0.046, N=63)$, stilbenoids $(F=8.163, P=0.006, N=$ $64)$, procyanidin B2 $(F=10.149, P=0.002, N=66)$, epicatechin gallate $(F=7.614, P=0.008, N=66)$, gallic acid hexoside $(F=$
4.411, $P=0.040, N=66)$, taxifolin pentoside $(F=14.020, P<$ $0.001, N=67)$, resveratrol $(F=8.030, P=0.006, N=67)$, an astringin dimer $(F=11.356, P=0.001, N=67)$, unknown $1(F=$ 4.088, $P=0.048, N=66)$, and unknown $2(F=4.564, P=0.037$, $N=67)$. For analyses of most compounds, significant interactions were observed between time and treatment $(P<0.05)$, with the exception of total coumaric acid derivatives, gallic acid hexoside, and a ferulic acid derivative. Spatial blocks were not significant and did not significantly interact with treatment; therefore, blocks were removed from ANOVAs.

TABLE 1. Compounds quantified in xylem sap, pulverized tissue, or cell walls using high-performance liquid chromatography ${ }^{\mathrm{a}}$

\begin{tabular}{|c|c|c|c|c|}
\hline Tissue, class & Compound & Retention Time & $\mathrm{UV} / \mathrm{Vis} \max$ & Mass \\
\hline \multicolumn{5}{|l|}{ Sap } \\
\hline \multirow{6}{*}{ Catechins and procyanidin } & Catechin & 8.685 & 278 & 290 \\
\hline & Epicatechin & 11.11 & 273 & 290 \\
\hline & Procyanidin B isomer & 4.96 & 279,310 & 594 \\
\hline & Procyanidin B1 & 7.69 & 277,320 & 578 \\
\hline & Procyanidin C1 & 8.1 & 276,326 & 866 \\
\hline & Procyanidin $\mathrm{C}$ isomer & 5.65 & 279,312 & 866 \\
\hline \multirow[t]{4}{*}{ Other flavonoids } & Engeletin & 16.65 & 261,360 & 434 \\
\hline & Isoquercitin & 14.16 & 360 & 464 \\
\hline & Quercetin & 17.315 & 300,365 & 302 \\
\hline & Miquelianin & 18.3 & 360 & 478 \\
\hline \multirow[t]{6}{*}{ Hydroxycinnamoyltartaric acids } & Caftaric acid isomer 1 & 6.63 & 278 & 312 \\
\hline & Caftaric acid isomer 2 & 7.07 & 278 & 312 \\
\hline & Coutaric acid isomer 1 & 10.43 & 271 & 296 \\
\hline & Coutaric acid isomer 2 & 10.8 & 271 & 296 \\
\hline & Fetaric acid isomer 1 & 11.625 & 280 & 326 \\
\hline & Fetaric acid isomer 2 & 12 & 280 & 326 \\
\hline \multirow[t]{4}{*}{ Hydrolyzable tannins } & Digalloyl quinic acid & 4.545 & 279 & 496 \\
\hline & Ellagitannin derivative 1 & 2.657 & 273 & 482 \\
\hline & Ellagitannin derivative 2 & 3.4 & 263 & 566 \\
\hline & Quinic acid & 2.355 & 263 & 192 \\
\hline Stilbenoid & Astringin & 18.18 & 283,345 & 406 \\
\hline \multirow[t]{5}{*}{ Unidentified } & Unknown 1 & 1.803 & 274 & 268 \\
\hline & Unknown 2 & 9.245 & 274 & 600 \\
\hline & Unknown 3 & 12.86 & 276,340 & 292 \\
\hline & Unknown 4 & 12.94 & 271 & 446 \\
\hline & Unknown 5 & 21.055 & 308 & 430 \\
\hline \multicolumn{5}{|l|}{ Xylem } \\
\hline \multirow[t]{7}{*}{ Catechins and procyanidin } & Catechin & 8.687 & 279 & 290 \\
\hline & Epicatechin & 11.497 & 273 & 290 \\
\hline & Epicatechin gallate & 14.524 & 272 & 442 \\
\hline & Procyanidin B1 & 7.727 & 279 & 578 \\
\hline & Procyanidin B2 & 9.757 & 277 & 578 \\
\hline & Procyanidin C1 & 8.073 & 279 & 866 \\
\hline & Procyanidin gallate & 10.817 & 276 & 730 \\
\hline \multirow[t]{3}{*}{ Other flavonoids } & Astilbin & 16.38 & 274,317 & 450 \\
\hline & Engeletin & 16.983 & 276 & 434 \\
\hline & Taxifolin pentoside & 24.587 & 274 & 436 \\
\hline \multirow[t]{4}{*}{ Stilbenoids } & Astringin & 18.313 & 273 & 406 \\
\hline & Astrigin dimer & 22.88 & 273 & 810 \\
\hline & Resveratrol & 17.417 & 279,315 & 228 \\
\hline & $\varepsilon$-Vinifern & 20.9 & 275,320 & 454 \\
\hline Coumaric acid derivative & Ferulic acid derivative & 14.507 & 275 & 476 \\
\hline Hydrolyzable tannin & Gallic acid glucoside & 6.227 & 279 & 332 \\
\hline Lignan & Chicoric acid & 28.113 & 279,314 & 474 \\
\hline \multirow{4}{*}{ Unidentified } & Unknown 1 & 21.01 & 274 & 386 \\
\hline & Unknown 2 & 26.423 & 279,314 & 506 \\
\hline & Unknown 3 & 27.78 & 285,318 & 700 \\
\hline & Unknown 4 & 28.95 & 288,319 & 682 \\
\hline \multicolumn{5}{|l|}{ Cell wall } \\
\hline \multirow[t]{3}{*}{ Coumaric acid derivatives } & Caffeic acid & 10.423 & 277,322 & 180 \\
\hline & Coumaric acid & 13.143 & 309 & 164 \\
\hline & Ferulic acid & 14.45 & 322,292 & 194 \\
\hline \multirow[t]{2}{*}{ Catechins } & Catechin & 8.824 & 278 & 290 \\
\hline & Epicatechin & 11.226 & 275 & 290 \\
\hline Hydrolyzable tannin & Gallic acid & 3.09 & 269 & 170 \\
\hline Stilbenoid & Piceid & 15.61 & 280,318 & 390 \\
\hline \multirow[t]{4}{*}{ Unidentified } & Unknown 1 & 21.26 & 274 & 386 \\
\hline & Unknown 2 & 23.328 & 274 & 328 \\
\hline & Unknown 3 & 23.82 & 281,324 & 330 \\
\hline & Unknown 4 & 24.467 & 274 & 342 \\
\hline
\end{tabular}

a Putative identifications were made based on matching of UV/Vis spectra $\left(\lambda_{\max }\right)$ or masses from liquid chromatography-mass spectrometry analyses. 
Concentrations of total phenolics, catechins and procyanidins, and stilbenoids were greater in $X$. fastidiosa infected plants than noninfected controls 2 and 4 months following inoculation treatments (Fig. 2). Non-catechin flavonoid concentrations were greater 2 months after inoculation treatments (Fig. 2). Levels of catechin, epicatechin, epicatechin gallate, procyanidin B2, procyanidin gallate, engeletin, taxifolin pentoside, astringin, astringin dimer, resveratrol, and a ferulic acid derivative were greater in

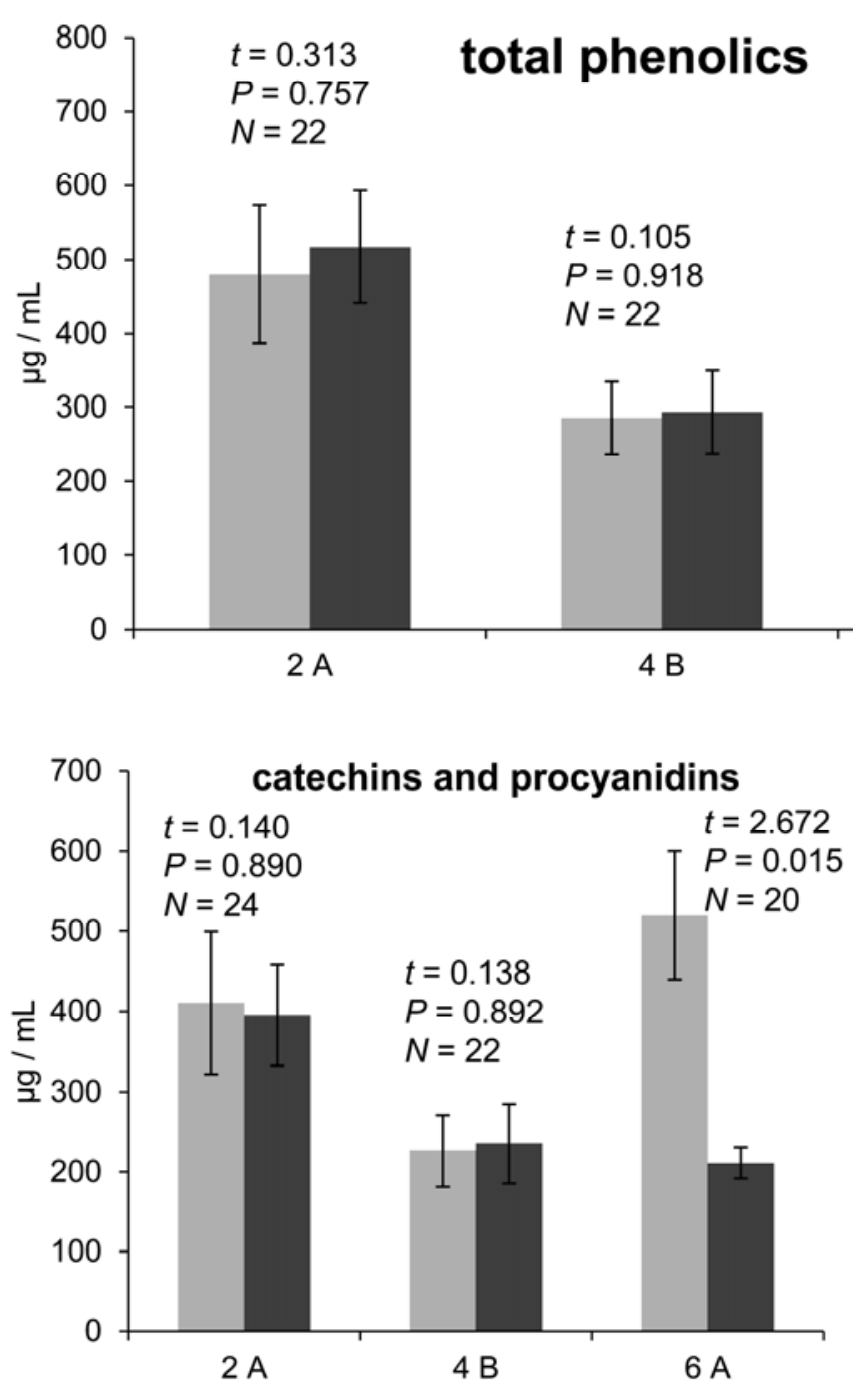

$t=3.313$

$P=0.006$

$N=17$
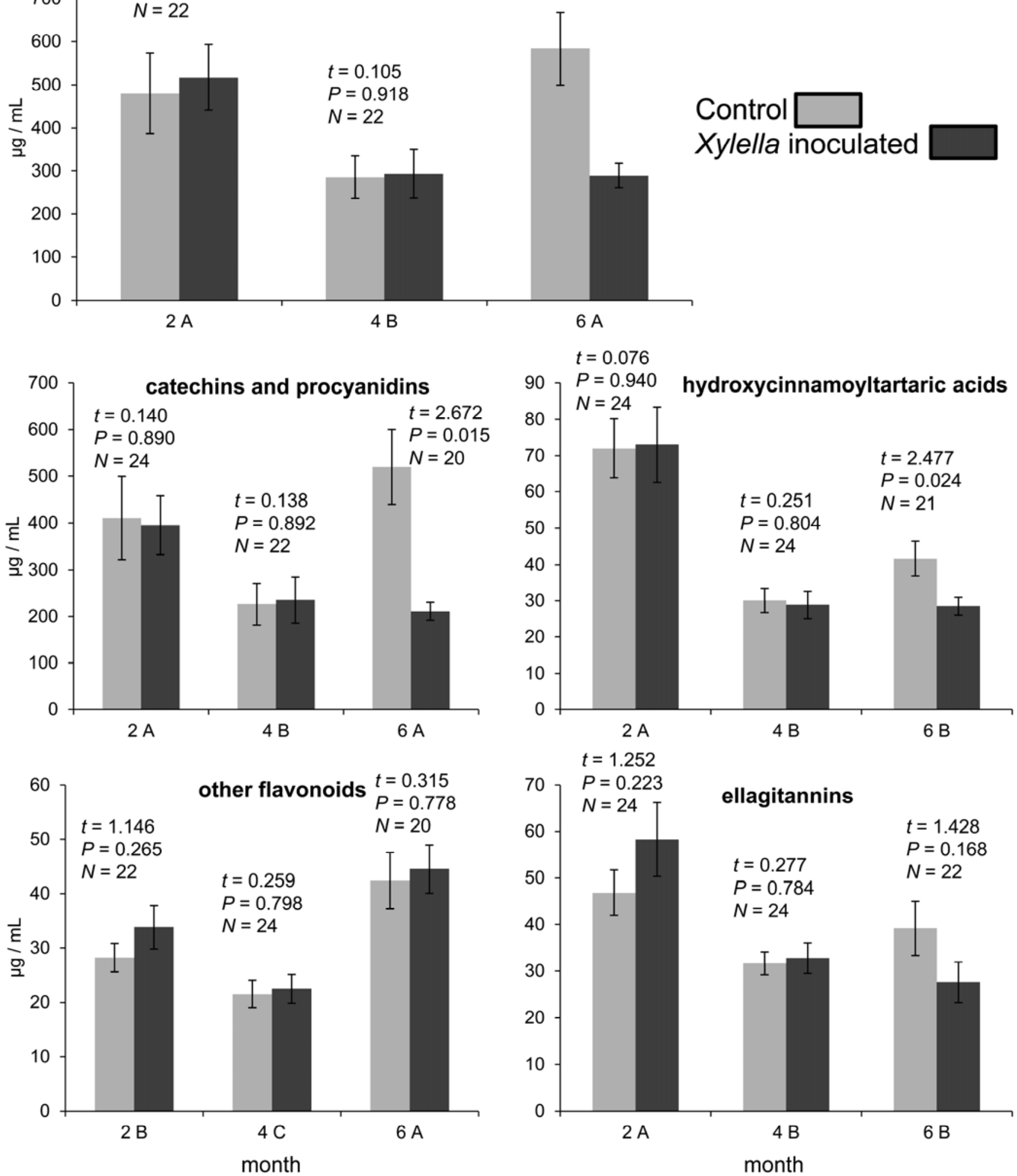

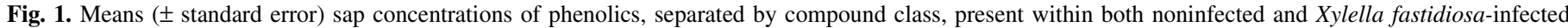

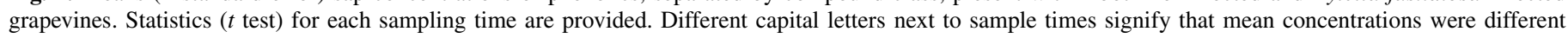
between sampling periods regardless of infection status. In all cases, $N=63$ to 73 . 
infected plants than controls 2 months postinoculation (Table 3). Epicatechin, epicatechin gallate, procyanidin B2, and taxifolin pentoside also were greater in infected plants than controls 4 months postinoculation (Table 3). Two unknowns were at greater levels in xylem tissue from infected plants 2 months postinoculation: unknown $2(t=2.239, P=0.036, N=23)$ and unknown $3(t=2.416, P=0.024, N=23)$. At 6 months postinoculation treatment, only taxifolin pentoside concentrations remained greater in infected plants than controls, whereas engeletin was present in greater amounts in noninfected plants than $X$. fastidiosa-infected plants (Table 3).

Xylem cell wall phenolics. In total, 11 phenolic compound peaks were quantified by HPLC from the cell-wall-bound phenolic extractions (Table 1). Lignin and condensed tannin content also were quantified by spectrophotometric methods. Repeatedmeasures ANOVAs determined that infection significantly increased levels of cell-wall-bound total phenolics $(F=8.345, P=$ $0.009, N=21)$ and total catechins $(F=8.953, P=0.007, N=22)$ but significantly decreased levels of condensed tannins $(F=$ $8.473, P=0.008, N=24)$. Individually, catechin $(F=9.018, P=$ $0.007, N=22)$, epicatechin $(F=5.227, P=0.033, N=22)$, and coumaric acid $(F=5.103, P=0.035, N=22)$ were at greater concentrations in $X$. fastidiosa-infected plants than noninfected plants throughout the entire experiment.

Nonrepeated-measures univariate ANOVAs confirmed that time was a major source of variation for levels of cell-wall-bound total phenolics $(F=24.899, P<0.001, N=74)$, catechins $(F=30.296$, $P<0.001, N=76)$, and coumaric acid derivatives $(F=13.014$, $P<0.001, N=75)$, as well as lignin $(F=47.238, P<0.001, N=$ $71)$ and condensed tannin $(F=45.676, P<0.001, N=77)$ (Fig. 1). All individual compound levels except caffeic acid also were significantly $(P<0.05)$ influenced by sampling time. $X$. fastidiosa infection significantly increased concentrations of cell-wallbound total phenolics $(F=10.313, P=0.002, N=74)$, total catechins $(F=10.409, P=0.002, N=76)$, coumaric acid derivatives $(F=5.854, P=0.018, N=75)$, catechin $(F=8.249, P=$
0.005, $N=76)$, epicatechin $(F=8.364, P=0.005, N=76)$, and coumaric acid $(F=6.846, P=0.011, N=76)$. Levels of condensed tannin were significantly lower in infected plants compared with noninfected plants $(F=4.304, P=0.042, N=77)$. Significant $(P<0.05)$ interactions of time and treatment were observed for all analyses of phenolic levels, with the exception of lignin and coumaric acid. Spatial blocks and block-treatment interactions were not significant. Therefore, blocks were removed from ANOVAs.

Total phenolics, catechins, and coumaric acid derivative concentrations were greater in cell walls of infected plants than in controls 2 months after inoculation treatments (Fig. 3). Total phenolics and catechins remained at greater concentrations in xylem cells walls 4 months postinoculation treatments (Fig. 3). Lignin and condensed tannin levels were greater in cell walls of noninfected plants than in infected plants 6 months after inoculation treatments (Fig. 3). Coumaric acid, ferulic acid, catechin, epicatechin, and gallic acid concentrations were greater in the cell walls of infected plants than controls 2 months postinoculation (Table 4). Concentrations of caffeic acid, epicatechin, and gallic acid were greater in the cell walls of infected plants than controls 4 months postinoculation (Table 4). Unknown 2 also was at greater levels in infected plants 2 months after inoculation $(t=$ 2.286, $P=0.032, N=24$ ).

PD symptoms and correlations with grapevine chemistry. Symptoms of PD in this experiment were not visibly observed until 4 months after inoculation. Symptom ratings 6 months postinoculation were significantly greater in infected $(2.33 \pm$ $0.31)$ than noninfected controls $(1.07 \pm 0.12)(t=4.140, P<$ $0.001, N=26$ ). Control plants exhibited minor leaf necrosis due to causes other than $X$. fastidiosa infection, because none of those plants tested positive for $X$. fastidiosa (whereas all X. fastidiosainoculated plants were positive for $X$. fastidiosa by both ELISA and PCR). Lignin, a major constituent of cell walls, had concentrations negatively associated with symptom ratings $(\rho=-0.512$, $P=0.010, N=24$ ) when both control and infected plants were

TABLE 2. Xylella fastidiosa infection effects on individual phenolic compound mean levels present within grapevine xylem sap at 2 , 4 , or 6 months after inoculation

\begin{tabular}{|c|c|c|c|c|c|c|c|c|c|}
\hline \multirow[b]{3}{*}{ Class, compound } & \multicolumn{9}{|c|}{ Mean $( \pm$ standard error $)$ levels $(\mu \mathrm{g} / \mathrm{ml})^{\mathrm{a}}$} \\
\hline & \multicolumn{3}{|c|}{2 months } & \multicolumn{3}{|c|}{4 months } & \multicolumn{3}{|c|}{6 months } \\
\hline & Control & Inoculated & $t$ & Control & Inoculated & $t$ & Control & Inoculated & $t$ \\
\hline \multicolumn{10}{|l|}{ Catechins and procyanidins } \\
\hline Catechin & $47.0 \pm 7$ & $132.0 \pm 33$ & $2.609 *$ & $35.5 \pm 3.7$ & $51.5 \pm 6.7$ & $2.207 *$ & $70.0 \pm 10.0$ & $51.5 \pm 13.5$ & 1.121 \\
\hline Epicatechin & $24.1 \pm 4.1$ & $18.2 \pm 2.2$ & 1.208 & $15.6 \pm 1.6$ & $17.5 \pm 2.9$ & 0.611 & $22.0 \pm 2.7$ & $15.8 \pm 2.3$ & 1.610 \\
\hline Procyanidin B1 & $21.0 \pm 6.0$ & $122.0 \pm 32.0$ & 1.258 & $82.7 \pm 18.2$ & $82.8 \pm 30.0$ & 0.005 & $146.0 \pm 33$ & $46.0 \pm 14$ & $2.245^{*}$ \\
\hline Procyanidin B2 & $49.0 \pm 10.4$ & $54.6 \pm 8.0$ & 0.393 & $16.8 \pm 2.5$ & $15.8 \pm 3.0$ & 0.263 & $83.4 \pm 20.5$ & $49.1 \pm 14.4$ & 1.219 \\
\hline Procyanidin $\mathrm{C}$ isomer & $25.4 \pm 5.3$ & $32.6 \pm 5.5$ & 0.948 & $23.6 \pm 5.4$ & $26.5 \pm 4.2$ & 0.398 & $47.4 \pm 7.7$ & $27.2 \pm 3.1$ & $2.037 *$ \\
\hline Procyanidin C1 & $54.8 \pm 12.3$ & $35.8 \pm 6.6$ & 1.332 & $54.2 \pm 16.5$ & $50.9 \pm 13.6$ & 0.147 & $151.0 \pm 28$ & $64.0 \pm 16.0$ & $2.225^{*}$ \\
\hline \multicolumn{10}{|l|}{ Other flavonoids } \\
\hline Engeletin & $6.21 \pm 0.74$ & $6.85 \pm 1.08$ & 0.486 & $7.39 \pm 1.09$ & $5.88 \pm 0.97$ & 1.006 & $6.92 \pm 1.08$ & $8.96 \pm 2.18$ & 0.928 \\
\hline Isoquercetin & $9.08 \pm 1.07$ & $8.78 \pm 1.04$ & 0.204 & $6.66 \pm 0.60$ & $8.18 \pm 1.34$ & 1.119 & $20.90 \pm 3.70$ & $19.40 \pm 1.3$ & 0.295 \\
\hline Quercetin & $9.70 \pm 1.30$ & $12.40 \pm 1.60$ & 1.344 & $2.77 \pm 0.51$ & $3.57 \pm 0.91$ & 0.806 & $8.21 \pm 1.25$ & $7.62 \pm 0.75$ & 0.354 \\
\hline Miquelianin & $5.39 \pm 0.55$ & $5.83 \pm 0.68$ & 0.499 & $4.69 \pm 0.66$ & $4.82 \pm 0.59$ & 0.140 & $8.22 \pm 1.21$ & $7.89 \pm 1.35$ & 0.176 \\
\hline \multicolumn{10}{|l|}{$\begin{array}{l}\text { Hydroxycinnamoyltartaric } \\
\text { acids }\end{array}$} \\
\hline Caftaric acid isomer 1 & $33.3 \pm 3.3$ & $32.6 \pm 5.0$ & 0.119 & $6.13 \pm 1.6$ & $4.47 \pm 0.67$ & 0.807 & $11.20 \pm 2.5$ & $4.80 \pm 0.6$ & $2.071^{*}$ \\
\hline Caftaric acid isomer 2 & $9.58 \pm 2.70$ & $8.69 \pm 1.96$ & 0.262 & $5.74 \pm 1.22$ & $4.96 \pm 0.96$ & 0.482 & $9.00 \pm 0.93$ & $5.52 \pm 1.03$ & $2.448^{*}$ \\
\hline Coutaric acid isomer 1 & $13.60 \pm 1.6$ & $14.00 \pm 2.3$ & 0.118 & $6.26 \pm 0.75$ & $7.97 \pm 1.79$ & 0.959 & $8.71 \pm 1.85$ & $5.30 \pm 0.51$ & 1.444 \\
\hline Coutaric acid isomer 2 & $5.61 \pm 0.70$ & $5.36 \pm 0.62$ & 0.274 & $5.10 \pm 0.50$ & $4.35 \pm 0.59$ & 0.988 & $7.24 \pm 1.09$ & $5.45 \pm 0.74$ & 1.196 \\
\hline Fetaric acid isomer 1 & $5.51 \pm 1.22$ & $6.20 \pm 1.03$ & 0.431 & $3.74 \pm 0.52$ & $3.38 \pm 0.60$ & 0.451 & $4.73 \pm 0.76$ & $3.37 \pm 0.45$ & 1.341 \\
\hline Fetaric acid isomer 2 & $4.37 \pm 0.74$ & $6.20 \pm 0.96$ & 1.520 & $3.13 \pm 0.28$ & $3.72 \pm 0.55$ & 1.017 & $4.25 \pm 0.42$ & $4.11 \pm 0.54$ & 0.211 \\
\hline \multicolumn{10}{|l|}{ Hydrolyzable tannins } \\
\hline Digalloylquinic acid & $10.4 \pm 1.3$ & $21.7 \pm 4.4$ & $2.540 *$ & $6.29 \pm 0.43$ & $7.00 \pm 1.02$ & 0.696 & $9.55 \pm 1.77$ & $4.84 \pm 1.22$ & 1.935 \\
\hline Ellagitannin derivative 1 & $11.6 \pm 1.1$ & $11.1 \pm 1.3$ & 0.319 & $7.98 \pm 0.51$ & $7.63 \pm 0.71$ & 0.399 & $5.82 \pm 1.10$ & $3.89 \pm 0.63$ & 1.323 \\
\hline Ellagitannin derivative 2 & $10.7 \pm 1.0$ & $12.0 \pm 1.6$ & 0.714 & $6.68 \pm 0.51$ & $7.20 \pm 0.87$ & 0.487 & $6.61 \pm 1.22$ & $4.76 \pm 0.98$ & 1.081 \\
\hline Quinic acid & $14.2 \pm 3.9$ & $13.5 \pm 1.7$ & 0.228 & $10.70 \pm 1.7$ & $11.00 \pm 1.3$ & 0.115 & $17.30 \pm 3.0$ & $14.10 \pm 3.0$ & 0.710 \\
\hline \multicolumn{10}{|l|}{ Stilbenoid } \\
\hline Astringin & $0.31 \pm 0.04$ & $0.58 \pm 0.12$ & $2.300 *$ & $0.58 \pm 0.10$ & $0.50 \pm 0.09$ & 0.558 & $0.84 \pm 0.10$ & $0.89 \pm 0.13$ & 0.317 \\
\hline
\end{tabular}

a Inoculated $=$ inoculated by $X$. fastidiosa; * indicates $P<0.050$. 
considered. Taxifolin pentoside concentrations from ground xylem tissue were positively associated with symptom ratings $(\rho=$ $0.527, P=0.014, N=21$ ) when both control and infected plants were considered. When correlations were made using infected plants only, the sap levels of miquelianin $(\rho=0.788, P=0.012$,
$N=9$ ); xylem tissue levels of total stilbenoids $(\rho=0.926, P=$ $0.008, N=6)$ as well as resveratrol $(\rho=0.797, P=0.032, N=7)$ and astringin dimer $(\rho=0.896, P=0.006, N=7)$; and total cellwall-bound phenolics $(\rho=0.749, P=0.013, N=10)$ were significantly positively associated with symptom severity ratings. No
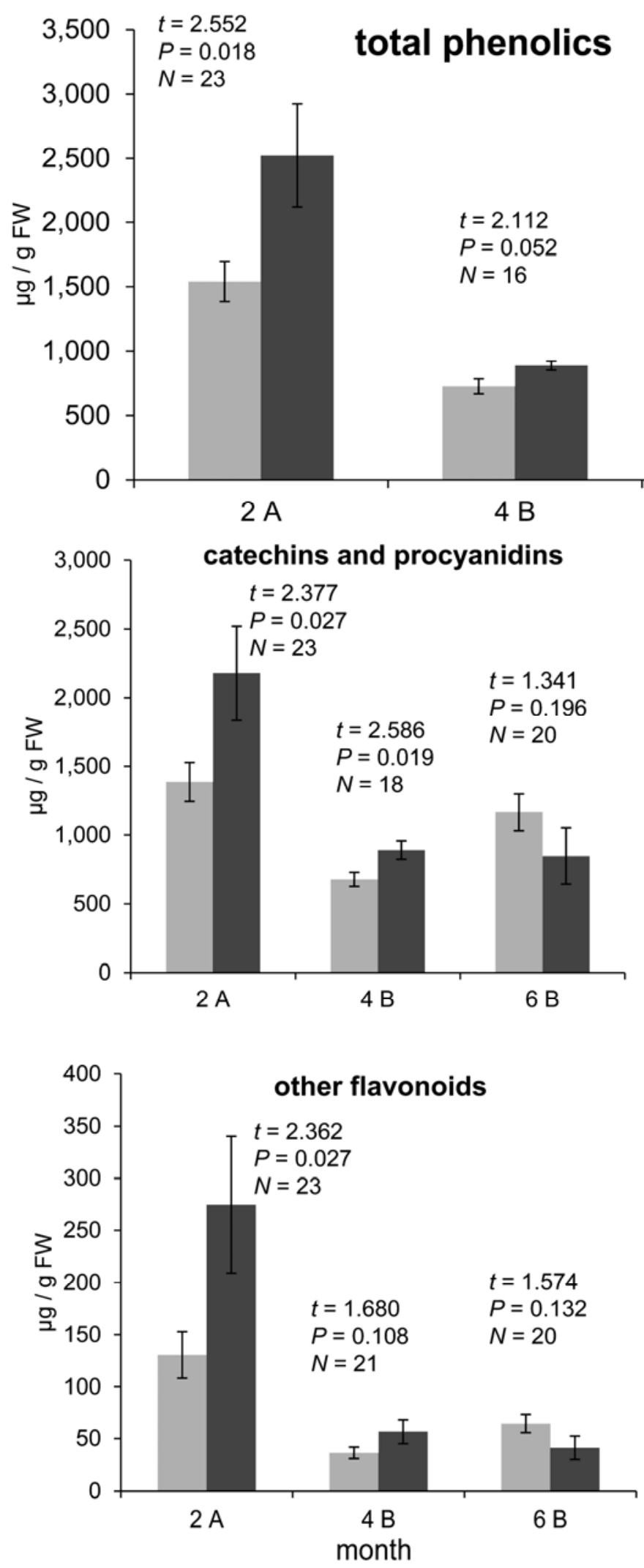

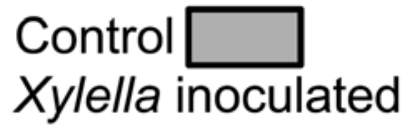

$N=16$
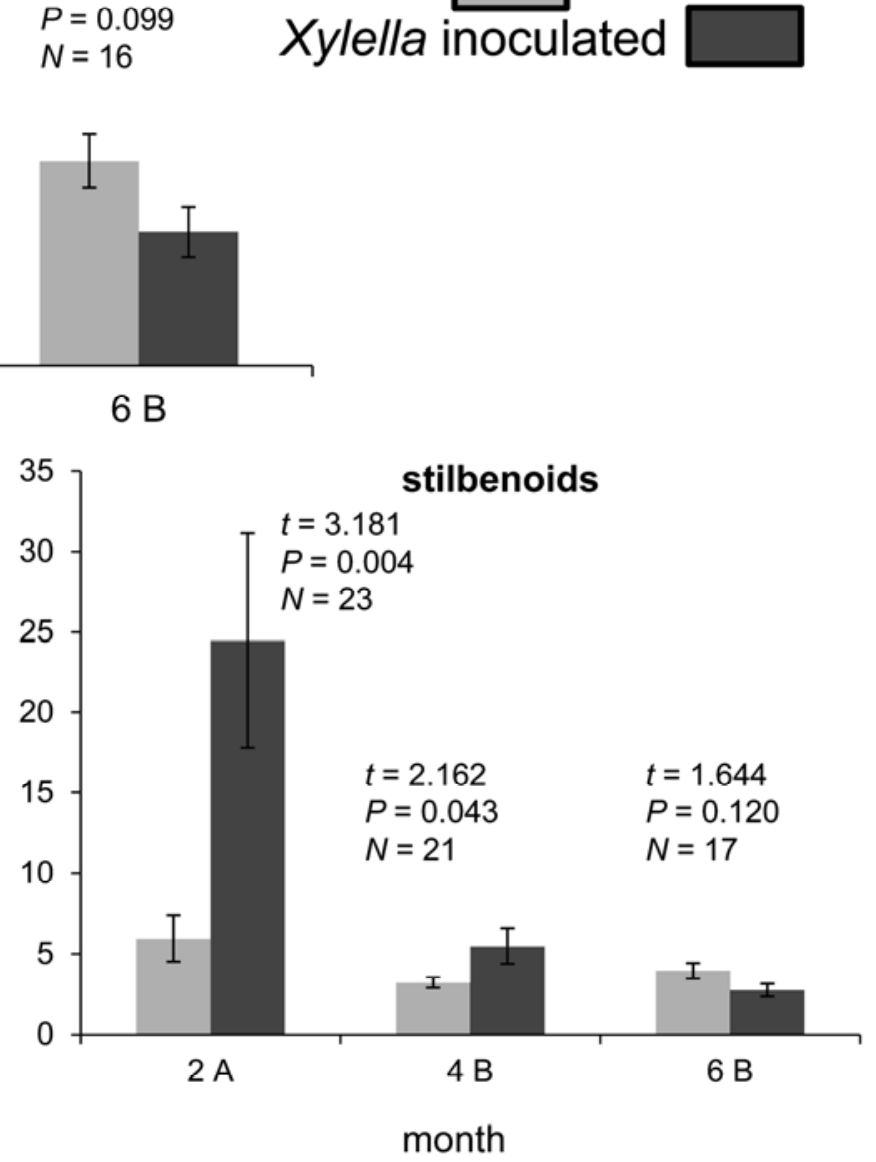

Fig. 2. Means ( \pm standard error) xylem concentrations of phenolics, separated by compound class, present within both noninfected and Xylella fastidiosa-infected grapevines. Statistics $(t$ test) for each sampling time are provided. Different capital letters next to sample times signify that mean concentrations were different between sampling periods regardless of infection status. In all cases, $N=58$ to 67 . 
other significant correlations were observed between PD symptom ratings and compound concentrations.

\section{DISCUSSION}

This research observed that grapevines might respond to $X$. fastidiosa infection initially (i.e., 2 months postinoculation) by producing increased amounts of phenolic compounds, including both phytoalexins (stilbenoids) and phytoanticipins (coumaric acid derivatives and flavonoids). As such, these results possible reveal that grapevines respond to $X$. fastidiosa with inductions of defense-associated compounds in the xylem. Previous studies have demonstrated the inducibility of phenolic compounds in grapevine xylem via abscisic acid application (29).

In general, compound levels in sap did not vary as much in response to $X$. fastidiosa infection as those from methanol extracts of pulverized xylem or from cell wall extractions. The relatively low water solubility of many phenolic compounds may have kept levels below detectable limits in xylem sap. Likewise, it is possible that environmental influences on xylem sap flow added extra variability to sap chemical analysis. Future studies examining host biochemical changes due to $X$. fastidiosa infections may prefer to focus on analyzing pulverized xylem tissue levels in addition to sap analyses because of these reasons. Ultimately, accumulation of phenolics likely occurs in the xylem tissues surrounding the xylem itself before importation into the sap and, therefore, the biochemical makeup of the surrounding xylem tissue should be of interest in comparable studies.

Regardless, increased stilbenoid production 2 months after $X$. fastidiosa infection was observed and likely significant because of previous associations found between stilbenoids and antibiotic effects $(2,18)$, even though levels were not increased 4 and 6 months after inoculation. A study by Maddox et al. (28) previously demonstrated that $X$. fastidiosa growth in vitro was significantly inhibited by considerable low $(200 \mu \mathrm{M})$ levels of resveratrol, which was the most abundant stilbenoid found in xylem tissue. Even though resveratrol was not observed at measureable levels in xylem sap, it was possible that grapevine

TABLE 3. Xylella fastidiosa infection effects on individual phenolic compound mean levels present within grapevine xylem tissue at 2 , 4, or 6 months after inoculation

\begin{tabular}{|c|c|c|c|c|c|c|c|c|c|}
\hline \multirow[b]{3}{*}{ Class, compound } & \multicolumn{9}{|c|}{ Mean $\left( \pm\right.$ standard error) levels $(\mu \mathrm{g} / \mathrm{g} \mathrm{FW})^{\mathrm{a}}$} \\
\hline & \multicolumn{3}{|c|}{2 months } & \multicolumn{3}{|c|}{4 months } & \multicolumn{3}{|c|}{6 months } \\
\hline & Control & Inoculated & $t$ & Control & Inoculated & $t$ & Control & Inoculated & $t$ \\
\hline \multicolumn{10}{|c|}{ Catechins and procyanidins } \\
\hline Catechin & $250 \pm 31$ & $423 \pm 84$ & $2.176^{*}$ & $293 \pm 25$ & $347 \pm 17$ & 1.654 & $537 \pm 61$ & $329 \pm 93$ & 1.909 \\
\hline Epicatechin & $188 \pm 38$ & $322 \pm 48$ & $2.214^{*}$ & $56.7 \pm 9.0$ & $90.4 \pm 14.3$ & $2.060 *$ & $114 \pm 21$ & $78 \pm 23$ & 1.062 \\
\hline Epicatechin gallate & $230 \pm 23$ & $359 \pm 56$ & $2.368^{*}$ & $90 \pm 8$ & $157 \pm 20$ & $3.439 * *$ & $95.3 \pm 14.0$ & $85.3 \pm 20.4$ & 0.408 \\
\hline Procyanidin B1 & $203 \pm 20$ & $290 \pm 48$ & 1.860 & $80 \pm 8$ & $120 \pm 20$ & 1.948 & $130 \pm 15$ & $102 \pm 22$ & 1.075 \\
\hline Procyanidin B2 & $141 \pm 20$ & $293 \pm 53$ & $3.019 * *$ & $32.9 \pm 6.2$ & $65.0 \pm 10.1$ & $2.845^{*}$ & $80.7 \pm 11.5$ & $91.0 \pm 23.6$ & 0.446 \\
\hline Procyanidin $\mathrm{C}$ isomer & $238 \pm 18$ & $271 \pm 35$ & 0.910 & $75 \pm 8$ & $117 \pm 17$ & $2.305^{*}$ & $134 \pm 15$ & $106 \pm 22$ & 1.081 \\
\hline Procyanidin gallate & $135 \pm 18$ & $221 \pm 39$ & $2.193^{*}$ & $45.9 \pm 6.4$ & $70.8 \pm 11.7$ & 1.954 & $72.3 \pm 10.4$ & $54.4 \pm 16.6$ & 0.954 \\
\hline \multicolumn{10}{|l|}{ Other flavonoids } \\
\hline Astilbin & $58.1 \pm 10.8$ & $89.2 \pm 16.8$ & 1.638 & $12.9 \pm 3.0$ & $15.6 \pm 3.7$ & 0.579 & $27.3 \pm 4.6$ & $23.4 \pm 11.1$ & 0.391 \\
\hline Engeletin & $69.6 \pm 12.2$ & $165 \pm 44$ & $2.390 *$ & $21.9 \pm 2.8$ & $36.2 \pm 7.7$ & 1.868 & $35.1 \pm 4.8$ & $13.1 \pm 2.8$ & $3.102^{* *}$ \\
\hline Taxifolin pentoside & $3.0 \pm 0.7$ & $21.0 \pm 6.7$ & $3.167 * *$ & $1.49 \pm 0.17$ & $4.81 \pm 1.32$ & $2.737 *$ & $2.14 \pm 0.32$ & $4.67 \pm 0.71$ & $3.799 * *$ \\
\hline \multicolumn{10}{|l|}{ Stilbenoids } \\
\hline Astringin & $0.271 \pm 0.045$ & $0.527 \pm 0.104$ & $2.495^{*}$ & $0.589 \pm 0.064$ & $0.617 \pm 0.149$ & 0.182 & $0.498 \pm 0.101$ & $0.522 \pm 0.153$ & 0.135 \\
\hline Astringin dimer & $0.78 \pm 0.11$ & $2.85 \pm 0.76$ & $3.197 * *$ & $0.60 \pm 0.10$ & $1.16 \pm 0.29$ & 1.975 & $0.857 \pm 0.155$ & $0.906 \pm 0.147$ & 0.198 \\
\hline Resveratol & $3.6 \pm 1.1$ & $19.0 \pm 6.0$ & $2.955 * *$ & $1.87 \pm 0.23$ & $3.39 \pm 0.82$ & 1.943 & $2.27 \pm 0.30$ & $1.70 \pm 0.32$ & 1.171 \\
\hline$\varepsilon$-Viniferin & $1.26 \pm 0.58$ & $2.13 \pm 0.47$ & 1.088 & $0.154 \pm 0.067$ & $0.304 \pm 0.212$ & 0.732 & $0.540 \pm 0.228$ & $0.290 \pm 0.286$ & 0.657 \\
\hline \multicolumn{10}{|l|}{ Coumaric acid derivative } \\
\hline Feulic acid derivative & $14.8 \pm 3.2$ & $42.6 \pm 14.0$ & $2.253^{*}$ & $15.1 \pm 2.6$ & $17.3 \pm 4.0$ & 0.471 & $39.5 \pm 8.6$ & $48.7 \pm 10.1$ & 0.660 \\
\hline \multicolumn{10}{|l|}{ Hydrolyzable tannin } \\
\hline Gallic acid hexoside & $14.4 \pm 3.9$ & $11.1 \pm 3.3$ & 0.600 & $9.44 \pm 2.60$ & $8.02 \pm 2.08$ & 0.407 & $33.9 \pm 6.5$ & $14.7 \pm 3.9$ & 1.970 \\
\hline \multicolumn{10}{|l|}{ Lignan } \\
\hline Chicoric acid & $7.73 \pm 0.48$ & $8.26 \pm 0.64$ & 0.678 & $6.00 \pm 0.51$ & $6.83 \pm 0.41$ & 1.233 & $6.31 \pm 0.54$ & $6.20 \pm 0.79$ & 0.118 \\
\hline
\end{tabular}

${ }^{\text {a }}$ Inoculated $=$ inoculated by $X$. fastidiosa; * and ** indicate $P<0.050$ and 0.010 , respectively.

TABLE 4. Xylella fastidiosa infection effects on individual phenolic compound mean levels present within grapevine xylem cell walls at 2, 4, or 6 months after inoculation

\begin{tabular}{|c|c|c|c|c|c|c|c|c|c|}
\hline \multirow[b]{3}{*}{ Class, compound ${ }^{\mathrm{b}}$} & \multicolumn{9}{|c|}{ Mean $\left( \pm\right.$ standard error) levels $(\mu \mathrm{g} / \mathrm{g} \mathrm{FW})^{\mathrm{a}}$} \\
\hline & \multicolumn{3}{|c|}{2 months } & \multicolumn{3}{|c|}{4 months } & \multicolumn{3}{|c|}{6 months } \\
\hline & Control & Inoculated & $t$ & Control & Inoculated & $t$ & Control & Inoculated & $t$ \\
\hline Caffeic acid & $5.80 \pm 0.92$ & $7.37 \pm 1.06$ & 1.102 & $3.63 \pm 0.53$ & $7.06 \pm 1.07$ & $3.005 * *$ & $4.82 \pm 0.89$ & $4.17 \pm 0.84$ & 0.504 \\
\hline Coumaric acid & $73.6 \pm 4.2$ & $95.1 \pm 6.9$ & $2.853^{* *}$ & $46.5 \pm 3.9$ & $51.4 \pm 4.3$ & 0.851 & $64.2 \pm 3.7$ & $68.1 \pm 6.2$ & 0.582 \\
\hline Ferulic acid & $74 \pm 16$ & $158 \pm 35$ & $2.443 *$ & $63.8 \pm 5.8$ & $60.8 \pm 6.1$ & 0.361 & $84.8 \pm 6.6$ & $74.3 \pm 5.5$ & 1.143 \\
\hline \multicolumn{10}{|l|}{ Catechins } \\
\hline \multicolumn{10}{|l|}{ Hydrolyzable tannin } \\
\hline $\begin{array}{l}\text { Gallic acid } \\
\text { Stilbenoid }\end{array}$ & $1,010 \pm 60$ & $1,420 \pm 160$ & $2.705^{*}$ & $633 \pm 43$ & $857 \pm 63$ & $2.998 * *$ & $1,740 \pm 190$ & $1,620 \pm 110$ & 0.470 \\
\hline Piceid & $47.3 \pm 3.1$ & $41.3 \pm 3.7$ & 1.215 & $31.8 \pm 3.5$ & $32.7 \pm 4.2$ & 0.170 & $40.6 \pm 2.6$ & $36.0 \pm 2.3$ & 1.252 \\
\hline
\end{tabular}

a Inoculated $=$ inoculated by $X$. fastidiosa; * and ** indicate $P<0.050$ and 0.010 , respectively.

b Abbreviation: deriv. = derivatives. 
hosts accumulated this and other stilbenoids in order to delay the progression of $X$. fastidiosa infections. Positive correlations were observed between stilbenoid concentrations of infected plants and symptom ratings, which suggests that severely diseased plants responded more strongly to $X$. fastidios $a$ with increased stilbenoid production than plants with more mild infections. However, mean stilbenoid concentrations of all infected grapevines did not differ than those in noninfected grapevines. Regardless, because $X$. fastidiosa infections can cause death in Pierce's diseased grapevines, $X$. fastidiosa likely possess mechanisms to ultimately overcome the negative effects that stilbenoids have on bacterial growth in vivo.
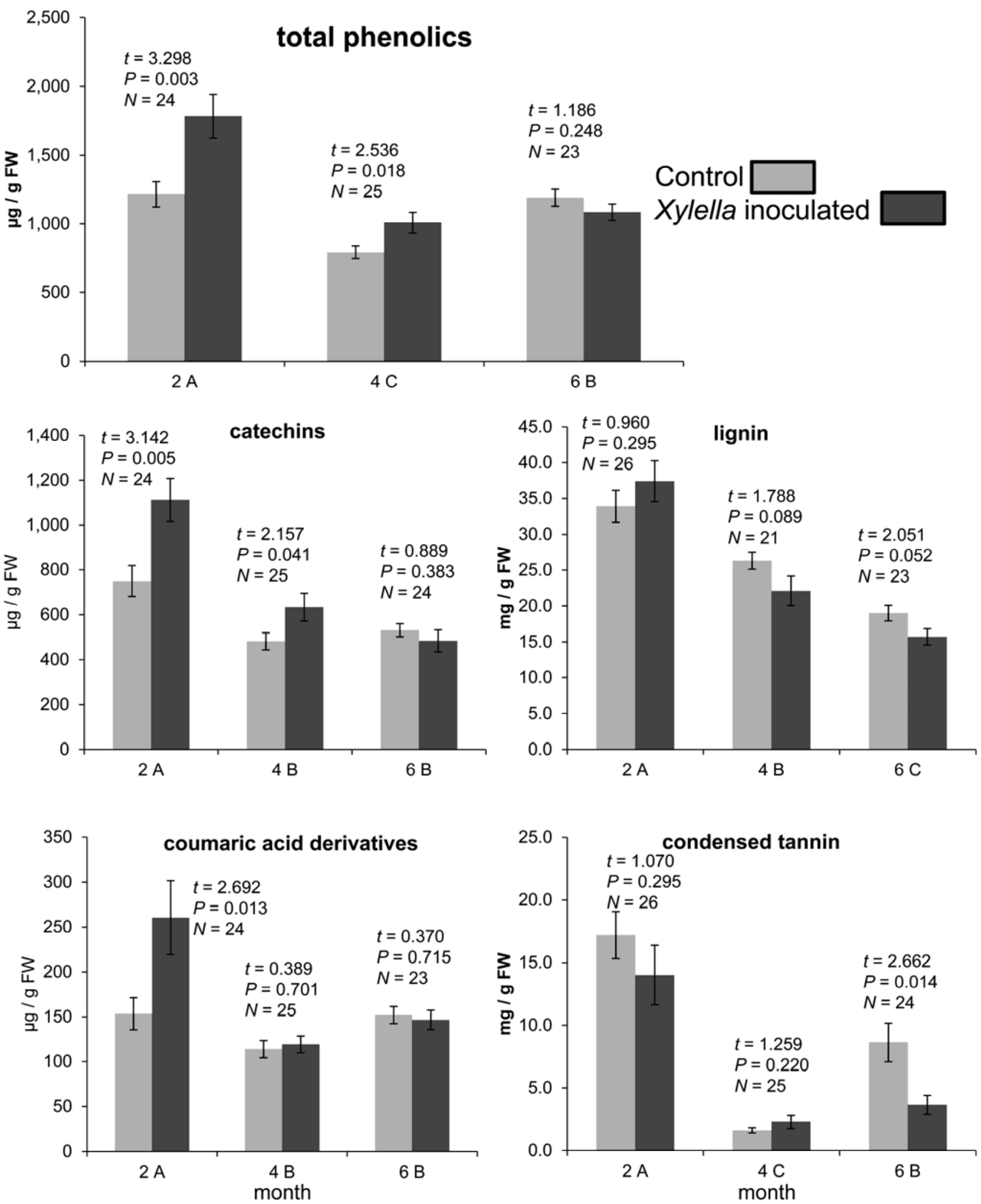

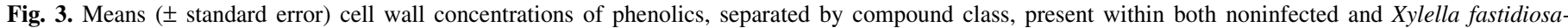

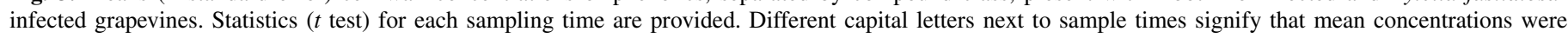
different between sampling periods regardless of infection status. In all cases, $N=71$ to 77 . 
Increased levels of catechins and procyanidins also were observed 2 months after $X$. fastidiosa inoculation, although increases were not observed 4 and 6 months after infection for all of these compounds. Catechin concentrations 2 months postinoculation $(131.5 \mu \mathrm{g} / \mathrm{ml})$ exceeded the concentration determined to inhibit $X$. fastidiosa growth $(200 \mu \mathrm{M}$ or $116 \mu \mathrm{g} / \mathrm{ml})$ by Maddox et al. (28). Considering that concentrations of catechin in noninfected grapevines $(46.5 \mu \mathrm{g} / \mathrm{ml})$ were well below inhibitory levels, these data suggest that, 2 months postinoculation, infected grapevines were successful at increasing sap catechin concentrations to levels detrimental to $X$. fastidiosa growth.

Increased concentrations of cell-wall-bound phenolics also were observed 2 months after inoculation (albeit not 4 or 6 months postinoculation), including phenolics that are precursors to lignin (coumaric acid and ferulic acid) and catechins. Increased levels of these compounds from cell wall extractions could suggest that cell walls of infected plants become more specialized in order to limit $X$. fastidiosa infection. Increased lignin levels could result in thicker cell walls that were more resistant to degradation by $X$. fastidios $a$ and, therefore, limit the ability of the pathogen to move into adjacent vessel elements and spread throughout the plant. Partial evidence for this may be negative correlations between lignin levels and symptoms. However, a lack of increased lignin or condensed tannin content suggests that chemical changes to cell walls might not be enough of a significant response to help limit $X$. fastidiosa infection.

Although phenolic compounds were increased in infected grapevines 2 months after $X$. fastidiosa inoculation, by 6 months, phenolic production was significantly diminished. All $X$. fastidiosa-infected plants at 6 months exhibited severe signs of stress such as abscission of $\approx 50 \%$ of leaves. Remaining leaves were highly necrotic, and stunting of new shoots was apparent. Under this state of severe stress, it was likely that negative trade-offs occurred between primary and secondary metabolism, with host resources shifted toward primary metabolism $(19,22,37)$. Hence, infected grapevines may have shifted away the resources needed to maintain a proper host defense response against $X$. fastidiosa in order to address a severe reduction in host primary metabolite production due to lost photosynthetic tissues (22,37). An exception to this may have been stilbenoid production and cell wall phenolic production, because disease severity at 6 months was positively associated with these compounds. Infected grapevines might have encountered a "point of no return" between 4 and 6 months whereby the disease was too far progressed to allow normal physiology to occur, the grapevines became symptomatic, and the plants entered a "survival mode" where most photosynthate was allocated for basic growth and maintenance (7).

Regardless, early induction of phenolic compounds may have benefited Thompson Seedless grapevines by delaying the progress of X. fastidiosa infections because of antibiotic activities. PD symptoms may have developed much quicker in the absence of induction of phenolic compounds in response to X. fastidiosa. This could explain, for instance, why certain grapevine cultivars, such as 'Chardonnay' or 'Crimson Seedless', exhibited greater $X$. fastidiosa titers and quicker symptom development than Thompson Seedless, whereas other cultivars, such as 'Rubired', may have slower symptom development and lower titers than Thompson Seedless (3). In other words, the capacity of particular cultivars to induce phenolics to higher concentrations may, in part, explain why some cultivars do not develop PD symptoms as quickly as others. If it is true that phenolics can delay or limit $X$. fastidiosa infections, then cultivars with naturally greater levels of phenolic induction following $X$. fastidiosa infection should be preferred over those with decreased phenolic production. Among other advantages, such cultivars could have increased instances of "winter curing", a phenomenon which has been documented to allow infected grapevines to recover from PD (25).
In conclusion, this study observed changes in phenolic compound production that occurred when grapevines were infected with $X$. fastidiosa. Grapevine hosts responded to $X$. fastidiosa infection initially by producing greater levels of phenolics in xylem tissue, likely for release into the xylem sap as an attempt to limit $X$. fastidiosa infection. However, efforts to limit $X$. fastidiosa infection ultimately failed in Thompson Seedless grapevines. Future studies should examine phenolic production in various cultivars of grapevine, both susceptible and resistant, to observe whether constitutive or inducible phenolic concentrations are associated with delaying, preventing, or abating PD symptoms.

\section{ACKNOWLEDGMENTS}

This work was funded by an appropriation made to the United States Department of Agriculture-Agricultural Research Service (USDA-ARS) Crop Disease, Pests, and Genetics Research Unit, Parlier, CA (USDAARS Research Project Number 5302-22000-008-00D). We thank N. Goodell, A. Fite, and G. Phillips for their assistance in the execution of this project.

\section{LITERATURE CITED}

1. Adrian, M., Jeandet, P., Veneau, J., Weston, L. A., and Bessis, R. 1997. Biological activity of resveratrol, a stilbenic compound from grapevines, against Botrytis cinerea, the causal agent for gray mold. J. Chem. Ecol. 23:1689-1702.

2. Ali, K., Maltese, F., Choi, Y. H., and Verpoorte, R. 2010. Metabolic constituents of grapevine and grape-derived products. Phytochem. Rev. 9:357-378.

3. Almeida, R., Rashed, A., and Daugherty, M. 2010. Evaluating variations in resistance and glassy-winged sharpshooter transmission rate among grapevine varietals. Pages 60-63 in: Proc. 2010 Pierce's Dis. Res. Symp. T. Esser and D. West, eds. California Department of Food and Agriculture, Time Printing, Inc., Sacramento, CA.

4. Baccari, C., and Lindow, S. E. 2011. Assessment of the process of movement of Xylella fastidiosa within susceptible and resistant grape cultivars. Phytopathology 101:77-84.

5. Basha, S. M., Mazhar, H., and Vasanthaiah, H. K. N. 2010. Proteomics approach to identify unique xylem sap proteins in Pierce's diseasetolerant Vitis species. Appl. Biochem. Biotechnol. 160:932-944.

6. Bonello, P., and Blodgett, J. 2003. Pinus nigra-Sphaeropsis sapinea as a model pathosystem to investigate local and systemic effects of fungal infection of pines. Physiol. Mol. Plant Pathol. 63:249-261.

7. Bonello, P., Gordon, T. R., Herms, D. A., Wood, D. L., and Erbilgin, N. A. 2006. Nature and ecological implications of pathogen-induced systemic resistance in conifers: A novel hypothesis. Physiol. Mol. Plant Pathol. 68:95-104.

8. Brown, C., Lynch, L., and Zilberman, D., 2002. The economics of controlling insect-transmitted plant diseases. Am. J. Agric. Econ. 84:279-291.

9. Chatelet, D. S., Wistrom, C. M., Purcell, A. H., Rost, T. L., and Matthews, M. A. 2011. Xylem structure of four grape varieties and 12 alternative hosts to the xylem-limited bacterium Xylella fastidiosa. Ann. Bot. 108:7385 .

10. Chen, J., Groves, R., Civerolo, E., Viveros, M., Freeman, M., and Zheng, Y. 2005. Two Xylella fastidiosa genotypes are associated with almond leaf scorch disease on the same location in California. Phytopathology 95:708-714.

11. Dandekar, A. M., Gilchrist, D., and Miller, T. 2011. Chimeric antimicrobial protein and polygalacturonase-inhibiting protein transgenic grapevines in field trial. Pages 101-106 in: Proc. 2011 Pierce's Dis. Res. Symp. T. Esser and D. West, eds. California Department of Food and Agriculture, Time Printing, Inc., Sacramento, CA.

12. Derckel, J. P., Baillieul, F., Manteau, S., Audran, J. C., Haye, B., Lambert, B., and Legendre, L. 1999. Differential induction of grapevine defenses by two strains of Botrytis cinerea. Phytopathology 89:197-203.

13. Dercks, W., and Creasy, L. L.1989. The significance of stilbene phytoalexins in the Plasmopara viticola grapevine interaction. Physiol. Mol. Plant Pathol. 34:189-202.

14. Gabler, F. M., Smilanick, J. L., Mansour, M., Ramming, D. W., and Mackey, B. E. 2003. Correlations of morphological, anatomical, and chemical features of grape berries with resistance to Botrytis cinerea. Phytopathology 93:1263-1273.

15. Gilchrist, D., and Lincoln, J. 2011. Field evaluation of grape plants expressing potential protective DNA sequences effective against Pierce's disease. Pages 125-127 in: Proc. 2011 Pierce's Dis. Res. Symp. T. Esser and D. West, eds. California Department of Food and Agriculture, Time 
Printing, Inc., Sacramento, CA.

16. Goetz, G., Fkyerat, A., Metais, N., Kunz, M., Tabacchi, R., Pezet, R., and Pont V., 1999. Resistance factors to grey mould in grape berries: Identification of some phenolics inhibitors of Botrytis cinerea stilbene oxidase. Phytochemistry 52:759-767.

17. Gutha, L. R., Casassa, L. F., Harbertson, J. F., and Naidu, R. A. 2010. Modulation of flavonoid biosynthetic pathway genes and anthocyanins due to virus infection in grapevine (Vitis vinifera L.) leaves. BMC Plant Biol. 10:187-205.

18. Hammerschmidt, R. 2004. The metabolic fate of resveratrol: Key to resistance in grape? Physiol. Mol. Plant Pathol. 65:269-270.

19. Herms, D. A., and Mattson, W. J. 1992. The dilemma of plants: To grow or defend. Q. Rev. Biol. 67:283-335.

20. Hopkins, D. 2001. Xylella fastidiosa. Pages 201-213 in: Laboratory Guide for Identification of Plant Pathogenic Bacteria, 3rd ed. N. W. Schaad, J. B. Jones, and W. Chun, eds. American Phytopathological Society, St. Paul, $\mathrm{MN}$.

21. Keller, M., Viret, O., and Cole, M. 2003. Botrytis cinerea infection in grape flowers: Defense reaction, latency and disease expression. Phytopathology 93:316-322.

22. Koricheva, J. 2002. Meta-analysis of sources of variation in fitness costs of plant antiherbivore defenses. Ecology 83:176-190.

23. Krell, R. K., Perring, T. M., Hashim-Buckey, J. M., and Pinckard, T. R., 2008. Susceptibility of Vitis vinifera L. cv. Redglobe and Thompson Seedless to Pierce's disease. Am. J. Enol. Vitic. 59:61-66.

24. Langcake, P. 1981. Disease resistance of Vitis spp. and the production of the stress metabolites resveratrol, $\varepsilon$-viniferin, $\alpha$-viniferin and pterostilbene. Physiol. Plant Pathol. 18:213-226.

25. Lieth, J. H., Meyer, M. M., Yeo, K. H., and Kirkpatrick, B. C. 2011. Modeling cold curing of Pierce's disease in Vitis vinifera 'Pinot Noir' and 'Cabernet sauvignon' grapevines in California. Phytopathology 101:14921500 .

26. Lin, H., Doddapaneni, H., Takahashi, Y., and Walker, M. A. 2007. Comparative analysis of ESTs involved in grape responses to Xylella fastidiosa infection. BMC Plant Biol. 7:8.

27. Lindow, S. 2011. Field evaluation of diffusible signal factor producing grape for control of Pierce's disease. Pages 154-157 in: Proc. 2011 Pierce's Dis. Res. Symp. T. Esser and D. West, eds. California Department of Food and Agriculture, Time Printing, Inc., Sacramento, CA.

28. Maddox, C. E., Laur, L. M., and Tian, L. 2010. Antibacterial activity of phenolic compounds against the pytopathogen Xylella fastidiosa. Curr. Microbiol. 60:53-58.

29. Meyer, M. M., and Kirkpatrick, B. C. 2011. Exogenous applications of abscisic acid increase curing of Pierce's disease-affected grapevines growing in pots. Plant Dis. 95:173-177.

30. Pezet, R., Gindro, K., Viret, O., and Spring, J. L. 2004. Glycosylation and oxidative dimerization of resveratrol are respectively associated to sensitivity and resistance of grapevine cultivars to downy mildew. Physiol. Mol. Plant Pathol. 65:297-303.

31. Pezet, R., and Pont, V. 1990. Ultrastructural observations of pterostilbene fungitoxicity in dormant conidia of Botrytis cinerea Pers. J. Phytopathol.
129:29-30

32. Rashed, A., Daugherty, M. P., and Almeida, R. P. P. 2011. Grapevine genotype susceptibility to Xylella fastidiosa does not predict vector transmission success. Environ. Entomol. 40:1192-1199.

33. Rusjan, D., Veberic, R., and Mikulic-Petkovsek, M. 2012. The response of phenolic compounds in grapes of the variety 'Chardonnay' (Vitis vinifera L.) to infection by phytoplasma Bois noir. Eur. J. Plant Pathol. 133:965974.

34. Sarig, P., Zutkhi, Y., Lisker, N., Shkelerman, Y., Ben-Arie, R., Bielski, R., Laing, W., and Clark, C. 1998. Natural and induced resistance of table grapes to bunch rots. Acta Hortic. 464:65-70.

35. Sbaghi, M., Jeandet, P., Faivre, B., Bessis, R., and Fournioux, J. C. 1995. Development of methods using phytoalexin (resveratrol) assessment as a selection criterion to screen grapevine in vitro cultures for resistance to grey mould (Botrytis cinerea). Euphytica 86:41-47.

36. Shiraishi, M., Chijiwa, H., Fujishima, H. and Muramoto, K. 2010. Resveratrol production potential of grape flowers and green berries to screen genotypes for gray mold and powdery mildew resistance. Euphytica 176:371-381.

37. Stamp, N. E. 2003. Out of the quagmire of plant defense responses. Q. Rev. Biol. 78:23-55.

38. Sun, Q. A., Greve, L. C., and Labavitch, J. M. 2011. Polysaccharide compositions of intervessel pit membranes contribute to Pierce's disease resistance of grapevines. Plant Physiol. 155:1976-1987.

39. Timperio, A. M., D’Alessandro, A., Fagioni, M., Magro, P., and Zolla, L. 2012. Production of the phytoalexins trans-resveratrol and delta-viniferin in two economy-relevant grape cultivars upon infection with Botrytis cinerea in field conditions. Plant Physiol. Biochem. 50:65-71.

40. Toscano, N. C., Hix, R., and Gispert, C. 2004. Riverside County glassywinged sharpshooter area-wide management program in the Coachella and Temecula Valleys. Pages 375-377 in: Proc. 2004 Pierce's Dis. Res. Symp. M. A. Tariq, S. Oswalt, P. Blincoe, A. Ba, T. Lorick, and T. Esser, eds. California Department of Food and Agriculture, Copeland Printing, Sacramento, CA.

41. Walker, A. 2011. Breeding Pierce's disease resistant winegrapes. Pages 204-209 in: Proc. 2011 Pierce's Dis. Res. Symp. T. Esser and D. West, eds. California Department of Food and Agriculture, Time Printing, Inc., Sacramento, CA.

42. Wallis, C., Eyles, A., Chorbadjian, R., McSpadden Gardener, B., Hansen, R., Cipollini, D., Herms, D. A., and Bonello, P. 2008. Systemic induction of phloem secondary metabolism and its relationship to resistance to a canker pathogen in Austrian pine. New Phytol. 177:767-778.

43. Wallis, C. M., Chen, J., and Civerolo, E. L. 2012. Zebra-chip diseased potato tubers are characterized by increased levels of host phenolics, amino acids, and defense-related proteins. Physiol. Mol. Plant Pathol. 78:66-72.

44. Wallis, C. M., Reich, R. W., Lewis, K. J., Huber, D. P. W. 2010. Lodgepole pine provenances differ in chemical defense capacities against foliage and stem diseases. Can. J. For. Res. 40:2333-2344.

45. Yang, L. T., Lin, H., Takahashi, Y., Chen, F., Walker, M. A., and Civerolo, E. L. 2011. Proteomic analysis of grapevine stem in response to Xylella fastidiosa inoculation. Physiol. Mol. Plant Pathol. 75:90-99. 